\title{
DE CASTILLA AL ORIENTE PORTUGUÉS: CUATRO MEDINENSES Y SUS ESCRITOS LUSO-CASTELLANOS
}

\author{
POR \\ Eduardo JAVIER Alonso Romo \\ Universidad de Salamanca
}

\section{RESUMEN}

En este artículo seguimos la huella de cuatro jesuitas, naturales de Medina del Campo, que marcharon a las misiones portuguesas de Asia y que, a pesar de su interés, no han sido estudiados hasta ahora. Entre los cuatro abarcan el primer siglo de historia de la Compañía de Jesús y, a través de ellos, se puede ver la evolución de la presencia hispano-lusa en aquellas tierras. Especial atención nos merecen sus escritos, buena muestra de bilingüismo luso-castellano, que constituyen nuestra fuente principal.

PAlABRAS ClAVE: Jesuitas, Asia, Misiones portuguesas, Medina del Campo, Pedro Morejón.

\section{Abstract}

The purpose of this essay is to trace the itinerary of four jesuit priests, born in Medina del Campo, whose life and works in the portuguese missions in Asia have not yet been studied. The sum of their lives embraces the first century of the history of the Society of Jesus and, through them we can observe the evolution of the spanish and portuguese presence in those lands. The article focuses on their writings, a valuable example of portuguese-spanish bilingualism.

KEY WORDS: Jesuits, Asia, Portuguese Missions, Medina del Campo, Pedro Morejón. 


\section{INTRODUCCIÓN}

En los últimos años ha atraído la atención de los estudiosos la proyección en América y Filipinas de los castellanos, y más en concreto de Valladolid y Medina del Campo ${ }^{1}$. Sin embargo, con pocas excepciones, la presencia de españoles en las Indias portuguesas ha sido generalmente desconocida o marginada. Nos referimos a las misiones que no dependían del Patronato español, sino del «Padroado português», aunque debemos recordar que entre 1580 y 1640 España y Portugal compartieron rey en la persona de Felipe II, III y IV.

Nuestro propósito en el presente trabajo es acercarnos, desde esa perspectiva, a la figura de cuatro hombres del siglo XVI, nacidos y criados en el corazón de Castilla, donde ingresaron en la Compañía de Jesús, y que saliendo de su tierra, marcharon al lejano Oriente, pasando a pertenecer a la Asistencia jesuítica de Portugal. Daremos razón de quiénes eran y cuál fue su relevancia personal. Pero, junto a su historia particular, nos detendremos especialmente en sus escritos: aquellos de los que tenemos noticia, que son cartas en su mayoría. En nuestra exposición, seguimos un orden cronológico en cuanto a su nacimiento: Jerónimo de Cuenca (1524-1588) conjuntamente con Andrés González (1526-1556) por diversas coincidencias en sus vidas, Francisco Carrión (1552-1590), y finalmente Pedro Morejón (1562-1639). Por lo que hemos podido ver, hasta ahora ninguno de ellos ha sido objeto de estudio más allá de breves referencias, que generalmente son antiguas, o están muy dispersas $^{2}$. Por otra parte, tampoco en su ciudad natal queda ninguna memoria histórica sobre ellos, según hemos comprobado en dicha localidad.

Gran parte de las fuentes principales para este estudio han sido editadas críticamente dentro de la colección Monumenta Historica Societatis Iesu (MHSI),

1 Cfr. Eufemio LoREnzo SANZ, «Los medinenses en el descubrimiento, conquista y colonización de América», en Historia de Medina del Campo y su tierra, Valladolid, Ayuntamiento de Medina del Campo, 1986, I, pp. 609-660; idem, «Los vallisoletanos en el Nuevo Mundo», en Los castellanos y leoneses en la empresa de las Indias, Valladolid, Junta de Castilla y León, 1993, pp. 293-326; $\mathrm{M}^{\mathrm{a}}$. I. GONZÁLEZ DEL CAMPO, «Valladolid y la proyección americana», en Historia de la Diócesis de Valladolid, Valladolid, Arzobispado-Diputación, 1996, pp. 331-356.

2 Ninguno de estos cuatro medinenses aparece, por ejemplo, en Q. ALDEA-T. MARÍN-J. VIVES (Dir.), Diccionario de Historia Eclesiástica de España, Madrid, CSIC, 1972-1987; ni tampoco en la obra de Gerald H. ANDERSON, Biographical Dictionary of Christian Missions, New York, Macmillan, 1997. En la Biblioteca de escritores de la Compañía de Jesús de J.E. de Uriarte y M. Lecina, aparecen Francisco Carrión y Jerónimo Cuenca, en el vol. II, pp. 138 y 321, respectivamente. En cambio, José SIMÓN DíAZ, sólo menciona a Pedro Morejón, en Jesuitas de los siglos XVI y XVII: escritos localizados, Madrid, UPSA-FUE, pp. 206-207. En La Enciclopedia Espasa hay una breve nota sobre Morejón, la cual contiene varios errores: vol. XXXVI, p. 977.

Órdenes religiosas

Hispania Sacra 54 (2002) 
en las series correspondientes a los documentos de la India ${ }^{3}$ y de Japón ${ }^{4}$, pero también nos han sido de utilidad otras series de Monumenta que iremos citando y algunas obras antiguas, especialmente las Cartas de Japão ${ }^{5}$, que nos ofrecen textos aún no publicados por los editores de MHSI. Cuando citamos a partir de estas fuentes, damos la referencia en el texto para no multiplicar innecesariamente las notas.

Aparte de otras más modernas, utilizamos como complemento preferente los trabajos históricos de tres jesuitas contemporáneos a los personajes que estudiamos, que escribieron sus obras en el mismo Oriente y que han sido editadas modernamente por el orientalista suizo Josef Wicki' ${ }^{6}$.

\section{DOS MEDINENSES DE LA PRIMERA HORA: JERÓNIMO DE CUENCA Y ANDRÉS GONZÁLEZ}

Desde finales de la Edad Media, Medina del Campo, gracias a sus famosas ferias que pronto desbordaron el comercio de la lana y los tejidos, se había transformado en el centro de negocios de Castilla. Su privilegiada situación fue convirtiendo a esta ciudad en eje para el intercambio de productos que llegaban de toda Europa, uniendo el tráfico de América vía Sevilla con plazas mercantiles como Amberes o Génova. Así se entiende que a mediados del siglo XVI su población alcanzara la cifra, muy considerable entonces, de unos 20.000 habitantes, aunque a partir de ese momento comenzará el declive de las ferias juntamente con la disminuición demográfica ${ }^{7}$. Recordemos también que en este tiempo, y hasta 1595, Medina y su tierra, aunque con bastante autono-

\footnotetext{
${ }^{3}$ Los textos jesuíticos del siglo XVI concernientes a la India fueron editados por Josef WICKI en los 18 volúmenes de la serie Documenta Indica, Roma, MHSI, 1948-1988; citamos esta obra con las siglas DI.

${ }^{4}$ Vid. Josef Franz SCHÜTTE, Monumenta Historica Japoniae, I, Roma, MHSI, 1975; los volúmenes II y III de esta serie llevan el título de Documentos del Japón y abarcan, respectivamente, los años $1547-1557$ y $1558-1562$; lo citamos como MHJ.

5 Cartas de Japão, Évora, 2 vols., 1598. Hay una edición facsímil publicada por Castoliva editora, Maia, 1997. Citamos esta obra con las siglas CJ, seguidas del volumen y la foliación correspondientes.

${ }^{6}$ Nos referimos a las siguientes obras: Alessandro VALIGNANO, Historia del principio y progreso de la Compañia de Jesús en las Indias Orientales (1542-64) [1583], Roma, IHSI, 1944, que citamos como VALIGNANO; Luís FRÓIS, História de Japam (1547-1593) [c.1594], Lisboa, Biblioteca Nacional, 5 vols., 1976-1984, que citamos como FRÓIS; y Sebastião GONÇALVES, Primeira parte da Historia dos Religiosos da Companhia de Jesus [...] nos reynos e provincias da India Oriental [c.1614], Coimbra, Atlântida, 3 vols., 1957-1962, que citamos como GonÇALVES.

7 Véase Auge de las ferias. Decadencia de Medina, que constituye el vol. II de la ya citada Historia de Medina de Campo y su tierra.
} 
mía, pertenecían a la diócesis de Salamanca, como veremos referido en los catálogos jesuíticos.

Todo lo anterior justifica el interés de la recién fundada Compañía de Jesús por abrir un colegio en la ciudad castellana. Después de la feliz experiencia de unas predicaciones allí -durante el verano y el adviento de 1550 -, en el verano de 1551 los jesuitas abrieron casa en Medina. Durante algunos meses se consideró esta comunidad como parte del colegio de Salamanca, bajo el rectorado del P. Miguel de Torres. Pero a principios de 1552 el P. Araoz le dio vida independiente, nombrando primer rector del colegio medinense a Pedro Sevillano, que ocuparía el cargo hasta $1560^{8}$. Enseguida se empezó a leer un curso de Artes, que fue el primero que se leyó en la provincia. A mediados de 1553 coincidieron en Medina Francisco de Borja, que se dirigía a Portugal, y Simão Rodrigues, que iba camino de Roma. Ese mismo año se puso la primera piedra del nuevo Colegio. En abril de 1554 Medina sería el escenario de un hecho importante cuando el P. Jerónimo Nadal, visitador de la península, dividió en tres provincias el territorio español: Castilla, Aragón y Andalucía.

Astrain, al señalar la rapidez con que brotaban vocaciones en todos los colegios que la Companía iba abriendo por aquellos años de mediados del siglo XVI, comenta: «Esto, que era como ley general, se cumplió muy especialmente en el colegio de Medina. En el mismo año de 1551, en que llegaron los nuestros, se les juntaron dos sacerdotes doctos de la misma ciudad, llamados Andrés González y Jerónimo Concha» ${ }^{9}$. Al año siguiente se les unieron otros cinco medinenses, entre ellos el joven José de Acosta (1540-1600) ${ }^{10}$, al que seguirían más tarde sus cuatro hermanos y su padre.

Jerónimo de Cuenca (o Concha) ${ }^{11}$, había nacido en Medina del Campo en febrero de 1524. Las pinceladas autobiográficas que esparce en algunas de sus cartas nos permiten reconstruir bastantes datos de su vida. Por ejemplo, que antes de ingresar en la Compañía, había sido discípulo indirecto de san Juan de Ávila, según cuenta al P. Laínez en una carta del 27 de noviembre de 1561,

8 Cfr. J. A. Polanco, Chronicon Societatis Iesu, Madrid, MHSI, 1894-1898, 6 vols.; en este caso IV, pp. 382-391: «De Collegio Methimnae Campi».

9 Antonio Astrain, Historia de la Compañia de Jesús en la Asistencia de España, Madrid, Razón y Fe, 7 vols., 1912-1925; en este caso I, pp. 312-313.

10 Señalemos aquí que José de Acosta, cuyo campo de misión estuvo en la América española, intervino en Oriente a través del Parecer y la Respuesta que escribió contra la opinión de quienes pretendían una evangelización a la fuerza por medio de la ocupación militar. Vid. Obras del P. José de Acosta, S.J., ed. de Francisco MATEOS, Madrid, BAE, 1954, pp. 33-345. Cfr. Fermín DEL PINO DíAZ, «El misionero español José de Acosta y la evangelización de las Indias Orientales», Missionalia Hispanica, 42 (1985), pp. 275-298.

11 En la India sería también llamado Jerónimo Vaz; no se debe confundir, sin embargo, con otro Jerónimo Vaz, portugués, que ingresó en la Compañía en 1579 y que también trabajó en la India.

Ordenes religiosas

Hispania Sacra 54 (2002) 
comentando cómo siendo ya sacerdote secular en Medina, conoció a unos discípulos avilinos:

\begin{abstract}
«Por emtão, eu sem saber que em a Igreja de Deus Noso Senhor ouvese tão santa Relegião, nem tal se praticava em muitas partes de Castilha, desejava muito que o Senhor me deparase alguns varões, santos clerigos, a quem eu seguise. Senão quando vierão a minha terra huns samtos varões, os quaes se ocupavam em santos exercicios, scilicet, em preguar, servir spritaes e dar todo bom exempro, e homens muito dados à oração e mortificação. Tenho por mim que erão dicipullos do Reverendo Pe. Avilla. Jumtei-me com elles; forão primcipio de minha conversão» (DI, V, p. 234) ${ }^{12}$.
\end{abstract}

En otra carta posterior da algunos detalles sobre su entrada en la Compañía a los 27 años:

\begin{abstract}
«Antes de aver colesio posavan los Padres en miña casa y de allí me fui con ellos por orden del Pe. Dotor Torres a una casa que un Rodrigo de Dueñas nos negoció a propósito asta que compramos unos chanos en que ecimos el colesio. Entré en la Compañía en el año de cinquenta y un, día de muestra Señora de la Assumpción, siendo ya sacerdote»(DI, X, p. 128).
\end{abstract}

De su ciudad natal, Jerónimo pasó a Plasencia, donde, junto con otros compañeros, participó en la fundación del Colegio jesuita, en septiembre de 1554: «De allí fiy por mandado del Pe. Francisco a Plasencia a un colesio que se quería fundar» (DI, X, p. 128). Sus inicios los refiere él mismo a Ignacio de Loyola en carta de 1 de enero de 1555 , cuyo original castellano se conserva ${ }^{13}$, en la cual señala que la Compañía había sido muy bien recibida en Plasencia, «que parece ser más milagro que obra de hombres, máxime a aquellos que conocen las enfermedades desta tierra, y las opilationes grandes de odios y rancores tan antiguos como en ella ay, por aver en ella vandos y passiones encendidas» ${ }^{14}$.

En dicha ciudad extremeña Jerónimo volvería a encontrarse con su paisano Andrés González cuando, a comienzos de 1555, ambos fueron elegidos para la prometedora misión de Etiopía por Francisco de Borja, comisario de la Compañía en España y Portugal ${ }^{15}$.

12 Cfr. nuestro trabajo «Huellas avilinas en Portugal y en el Oriente portugués», en Actas del Congreso Internacional El Maestro Ávila, Madrid, EDICE, 2001 (en prensa).

13 Vid. Epistolae Mixtae ex variis Europae locis ab anno 1537 ad 1557 scriptae, Madrid, MHSI, 1899-1901, 5 vols.; en este caso vid. IV, pp. 494-501.

${ }^{14}$ Epistolae Mixtae, IV, p. 497.

15 Polanco, sin embargo, parece olvidar la estancia del P. Jerónimo en Plasencia: «Ad missionem Aethiopiae tres misit P. Franciscus, juxta P. Ignatii praescriptum; unus eorum erat Pater, cognomine Gonzalez, qui Abulae residebat; secundus Pater, cognomine Cuenca, Methimna ad hanc missionem profectus» (Chronicon, V, p. 545). 
Andrés González había nacido en Medina del Campo en 1526 y, como ya hemos señalado, allí mismo ingresó en la Compañía en 1551. A mediados de 1554 pasó a Ávila, al ser nombrado por el P. Nadal primer rector del recién fundado colegio de la Compañía ${ }^{16}$. En la ciudad amurallada vivió con el hermano Ramírez, zamorano, y con Juan García, un candidato que procedía del colegio de la Doctrina. Aunque no hemos encontrado ninguna noticia al respecto, no parece improbable que en este tiempo conociera a Teresa de Jesús, quien poco después, en la primavera de 1555, sería dirigida por el P. Diego de Cetina, y enseguida por Juan de Prádanos y otros cuya historia es bien conocida ${ }^{17}$.

Los dos únicos textos conservados de Andrés González corresponden precisamente a su etapa abulense. Se trata de dos cartas dirigidas a Ignacio de Loyola, cuyo texto autógrafo castellano fue publicado en Epistolae Mixtae ${ }^{18}$. En la primera, fechada el 12 de octubre de 1554, relata los inicios del colegio de Ávila, fundado bajo los auspicios de Hernando Álvarez del Águila, así como sus propias actividades: "Yo me ocupo en oir la theología que se lee en santo Thomás, monesterio de los dominicos, y en confesiones y ocupaciones ordinarias». En este tiempo le tocó sufrir el ataque de un franciscano que, desde el púlpito, habló contra la Compañía:

\footnotetext{
«dijo que san Francisco era buen médico, y no como agora, que andan con buenas ropas de refino, y camisas y calças atadas, y no quieren limosnas, sino renta; y una destas dos cosas: o que pluguiese a Dios que debajo desta santidad no estuviese el demonio, o que ansí avian empezado los alemanes ${ }^{19}$.
}

La segunda carta es de 15 de enero de 1555 y trata de los ministerios realizados en la ciudad castellana. Probablemente Andrés González había pedido marchar a las Indias ${ }^{20}$. El caso es que poco después Francisco de Borja lo destinó a Etiopía y lo envió a Lisboa a través de Plasencia. Cuando Francisco de Borja llegó a Plasencia, los jesuitas que él había destinado para la misión del Preste ya habían partido hacia la capital portuguesa. Desde Plasencia escribe Borja a Ignacio de Loyola el 23 de marzo de 1555, informándole de las razones de su elección ya que suponía cambios de última hora:

\footnotetext{
16 POLANCO, Chronicon, IV, p. 489.

17 Cfr. Cándido DE DALMASES, «Santa Teresa y los jesuitas. Precisando fechas y datos», AHSI, 35 (Roma, 1966), pp. 347-378.

18 Vid. Epistoale Mixtae, IV, pp. 392-393 y 516-520, respectivamente.

${ }^{19}$ Epistolae Mixtae, IV, p. 393.

20 Valdivia señala a este respecto: «En este año se le cumplieron al P. Andrés González sus antiguos y santos deseos de pasar a las Indias, a la conversión de los infieles y a padecer algo por su amor», en Colegio de Avila, f. 241; apud Chronicon, VI, p. 618, n. 2.

Órdenes religiosas

Hispania Sacra 54 (2002)
} 


\begin{abstract}
«No se han embiado los que de ay me embiaron nombrados, pues se dexava a mi libertad, paresciéndome que convenían más estos [...] el P. Gonçález, en lugar del P. Sancta Cruz, porque tiene mucha más experiencia en cosas eclesiásticas, y ha oído más theología [...]. El P. Cuenca va en lugar del P. Casellas; porque ha studiado el curso de artes, y ha oído alguna cosa de theología, lo que no ha Casellas, y es para más trabajos. Todo esto ha hecho, juzgando que V.P. lo mandara así, si se hallare presente» ${ }^{21}$.
\end{abstract}

Vemos, por tanto, que en principio ni Jerónimo de Cuenca ni Andrés González estaban destinados a la misión de Etiopía; enseguida veremos que de hecho ninguno de los dos llegaría nunca a pisar la tierra del Preste Juan. De momento marcharon hacia Lisboa, en compañía del hermano Alfonso López, que llevaba el destino de consejero teológico.

Poco tiempo se demoraron en la ciudad lisboeta, pues el 1 de abril de 1555 embarcaron, repartidos en cuatro naves: Jerónimo embarcó en la nave «Assunção», y Andrés en la «Conceição»"22. En total eran doce misioneros los enviados en aquella expedición: diez destinados a Etiopía y dos para la India. Además de los PP. Jerónimo y Andrés, los otros eran los padres Melchior Carneiro - que en Goa sería consagrado obispo-, António de Quadros - como provincial de la futura provincia de Etiopía-, Manuel Fernandes, Pascual Catalán, Miguel Barul y Joannes Bocchio; y los hermanos Alfonso López, António da Costa, Marcos Nunes y José Ribeiro. Viajaban en cada barco dos padres y un hermano. De todos ellos escribía el infante d. Luís a D. Pedro Mascarenhas, virrey de la India: «S. A. vos manda este anno doze Padres da Companhia de Jesus, que são para converter o mundo» (DI, III, p. 267). Llevaban consigo las Constituciones y las Reglas, recién elaboradas por san Ignacio y que serían promulgadas en la India ese mismo año.

La nave «Conceição», en la cual iban Andrés González, Alfonso López y Pascual Catalán, se adelantó a las otras en las islas Canarias, pero el 22 de agosto, ya en el Océano Índico, quedó encallada en unos bajíos, llamados de Pero dos Banhos, junto a las islas Maldivas. Unos trescientos hombres lograron alcanzar un islote desierto y salvar un poco de bizcocho mojado, carne medio podrida y un poco de vino. El capitán, el piloto y algunos marineros se embarcaron en el bote y consiguieron llegar al puerto de Goa. El capitán ofreció a los jesuitas llevarlos en su barco, pero ellos rehusaron, prefiriendo permanecer con las más de doscientas personas que aún quedaban esperando socorro. Poco después se hicieron a la mar otros cincuenta hombres en una embarcación que construyeron con los restos de la nao.

${ }^{21}$ Borgiae Monumenta, Madrid, MHSI, 1894-1911, 5 vols; en este caso III, pp. 204-205.

22 Las fuentes citan también estas dos embarcaciones con los nombres de «Algaravia-a-Velha» y «Algaravia-a-Nova», respectivamente. 
Jerónimo de Cuenca escribe al respecto: «Díjonos el capitán, porque le repriendimos, que porqué de tres Padres no nos traya uno? Dijo que ya él lo rogava el P. Gonçalez que venía por retor de su nao; y dijo que no quería, sino que allí avía de morir con aquella gente, que no la quería desamparar»( DI, III, pp. 293-294). Aunque las fuentes no lo señalan, está claro que con su generoso gesto al mismo tiempo le estaba dejando su lugar a otro, que de este modo se pudo salvar.

A través de Bartolomé Alcázar sabemos que los tres jesuitas «por medio de los que se salvaron en el esquife escribieron a los Padres del Colegio de Goa una carta» ${ }^{23}$, pero dicho documento - sin duda de gran interés- no ha llegado hasta nosotros. Sí conservamos, en cambio, las cartas en las que durante varios meses los jesuitas de Goa manifestaban sus esperanzas de que sus compañeros aún pudieran ser rescatados ${ }^{24}$.

A pesar de que el gobernardor de la India envió dos barcos en su ayuda, no pudieron encontrarlos. Entretanto los naúfragos habían construído otra embarcación con la que arribaron a otro islote, igualmente desierto, donde los tres jesuitas murieron de hambre, junto a la mayoría de la gente, a lo largo del verano de 1556; Andrés González, a quien podemos considerar «mártir de la caridad $»^{25}$, tenía treinta años.

Otros pocos, sin embargo, volvieron a intentar el viaje y consiguieron llegar a Goa el 27 de noviembre de 1556, quince meses después del naufragio ${ }^{26}$. Estos testigos de excepción informaron sobre la muerte de los religiosos. Acerca del P. González narraron la terrible anécdota de su muerte, al perseguir un cangrejo y caer en tierra por la extrema debilidad, resultado de las carencias sufridas, diciendo estas palabras, que las fuentes portuguesas nos transmiten en castellano como prueba de autenticidad: «Válgame el Señor Dios y la Virgen María, que me muero de hambre» ${ }^{27}$.

23 Bartholome AlCÁzAR, Chrono-Historia de la Compañia de Jesus, en la Provincia de Toledo, Madrid, Juan Garcia Infançon, 1710, I, p. 269, dentro del capítulo dedicado al «Naufragio del $\mathrm{H}$. Alonso Lopez, estudiante theologo, en la carrera de la India, por obsequio de la charidad» (vol. I, pp. 267-274). Alcázar subraya que «los tres Padres de la Compañía de Jesús se quedaron en la isla, no por necesidad, sino por elección [...] pareciéndoles que debían arriesgarse a la muerte, antes que faltar a la caridad de sus prójimos en necesidad tan extrema»; cfr. Balthasar TELlEZ, Chronica da Companhia de Jesu na Provincia de Portugal, Lisboa, Paulo Craesbeeck, 1645-1647, II, pp. 550-556.

${ }^{24}$ Cfr. DI, III, pp. 326-327, 354, 356, 373-376, 381, 429-430 y 442-443.

${ }^{25}$ Cfr. Élesban DE Guillermy, Ménologe de la Compagnie de Jésus. Assistance d'Espagne, Paris, Leroy, 1902, II, pp. 343-345.

${ }^{26}$ Cfr. DI, III, pp. 603-605; VALIGNANO, pp. 311-313; y GONÇALVES, II, pp. 143-146.

27 GONÇALVES, II, p. 146; y también Francisco de SOUSA, Oriente conquistado a Jesus Cristo [1710], Porto, Lello\&Irmão, 1978, p. 117.

Órdenes religiosas

Hispania Sacra 54 (2002) 
La noticia de la pérdida de los tres misioneros causó gran conmoción, no sólo en la India, sino también en Europa ${ }^{28}$. Posteriormente estas informaciones aparecerán en una relación del viaje atribuida a un tal Manuel Rangel ${ }^{29}$, que dos siglos después sería recogida y publicada por Gomes de Brito dentro de la História trágico-marítima, célebre en la literatura portuguesa. Este relato, en el cual Andrés González es llamado Gonçalo Vaz, nos ofrece algunos detalles de las personas y la vida de los náufragos:

«Os padres apóstolos eram três, os dous de missa e o outro não. O padre Gonçalo Vaz [Andrés González] era pregador, e o outro se chamava Pascoal, e o pregador nos pregava sempre aos domingos e festas, e era muito devoto de Nossa Senhora, e nos encomendava que sempre andássemos aparelhados para quando quer que nos chamasse Deus» 30 .

Del naufragio de la nave Conceição también se ocuparían, además de otros, el famoso cronista portugués Diogo do Couto en sus Décadas y el historiador Francisco de Andrade 31 .

Por su parte, Jerónimo de Cuenca navegó en compañía de otros dos jesuitas: el belga Joannes Bocchio y el portugués Marcos Nunes. Éste escribe que durante el viaje se empleaban en «la doctrina y letanyas todos los días, y predicacyón a los domingos y fiestas, unas vezes el Padre Quenca, otras vezes yo, porqu'el Padre Maestro Juan carescía de lenguaje portugués» (DI, III, p. 438); esto supone que en aquel tiempo Jerónimo ya dominaba la lengua lusa lo bastante como para predicar en ella. El mismo Marcos Nunes nos informa de que fueron numerosas las confesiones, de modo que en el barco «ya no avía jugar, mas tomavam los naypes y los echavan a la mar, de lo qu'el Pe. Girónimo de Quenca fue siempre muy zeloso» (DI, III, p. 442).

Arribaron al puerto de Goa el 7 de septiembre de 1555 y, una vez en la ciudad, peregrinaron al sepulcro de Francisco Javier, fallecido tres años antes. Comenta el P. Jerónimo: «vimos su cuerpo entero como si acabara de spirar, y

28 Cfr. Polanco, Chronicon, Madrid, MHSI, 1898, VI, pp. 618, 778 y 838. Desgraciadamente, éste no fue el único naufragio sufrido por los jesuitas en sus viajes al Oriente: hubo otros en 1561, 1566 , en 1585 , etc.

${ }^{29} \mathrm{Cfr}$. Giulia LANCIANI, Os relatos de naufrágios na literatura portuguesa dos séc. XVI e XVII, Lisboa, ICP-Biblioteca Breve, 1979, pp. 23-25. Esta profesora piensa que el relato habría sido escrito hacia 1620 por un anónimo jesuita portugués.

30 Vid. Bernardo GOMES DE BRITO, História trágico-marítima [1736], Mem Martins, EuropaAmérica, 1983, I, pp. 110-133: «Relação do naufrágio da nau Conceição de que era capitão Francisco Nobre, a qual se perdeu nos baixos de Pêro dos Banhos aos 22 dias do mês de Agosto de 1555. Escrita por Manuel Rangel, o qual se achou no naufrágio e foi depois ter a Cochim em Janeiro de 1557».

31 Diogo do CouTo, Década Sétima. Parte primeira [1616], Lisboa, Sam Carlos, 1974, pp. 155162; y Francisco de ANDRADE, Crônica de D. João III [1613], Coimbra, 1796, 4ª parte, cap. 118. 
le besamos sus pies» (DI, III, p. 292). Una vez repuesto del viaje, a finales de octubre fue destinado provisionalmente a Baçaim para predicar y confesar. El 12 de noviembre de 1555, cuando llevaba allí dos semanas, escribe una carta a Francisco de Borja y otros jesuitas españoles, pidiendo que «se lea en Medina del Campo, y Plasencia y en Salamanca» (DI, III, p. 296). Se conserva el autógrafo castellano con algunos lusismos en uno de cuyos párrafos el $\mathrm{P}$. Jerónimo se atreve a imitar el criollo hablado por los indios, para terminar con estas curiosas palabras: «Es acá en estas partes muy aceta la lengua castillana que se pierden por ella: por eso venga gente». Comenta además: «aora enpiezo a deprender la lingua abezina: para el Preste yremos en el mes de Enero de 1556 años» (DI, III, p. 296) ${ }^{32}$. De hecho, en 1556 llegaron a Goa el resto de los jesuitas destinados a Etiopía, encabezados por el patriarca João Nunes Barreto y el obispo Andrés de Oviedo. Sin embargo, Jerónimo de Cuenca permanecería en la India el resto de su vida sin llegar a participar de manera directa de esta misión, que, como es sabido, finalmente resultaría malograda ${ }^{33}$.

De su etapa en la India, además de dos textos actualmente perdidos ${ }^{34}$, se conservan también otros que pasamos a reseñar por orden cronológico:

- Carta en portugués a los jesuitas de Goa, escrita en Cochim el 21 de abril de 1560, por encargo de Melchior Nunes Barreto ${ }^{35}$. En ella el P. Cuenca narra los ministerios realizados por los jesuitas en Cochim durante la cuaresma y la semana santa, abundando en la descripción de algunas celebraciones litúrgicas. Particular interés tiene su decripción de la ceremonia del viernes santo, por su carácter parateatral ${ }^{36}$.

\footnotetext{
32 Ésta, al ser incluida en la Chono-Historia del P. Alcázar, es la única carta del P. Cuenca citada por Sommervogel; vid. C. SOMmervogel-E. M. Rivière, Bibliothèque de la Compagnie de Jésus, Bruxelles-Paris-Louvain, Province de Belgique, 1890-1960, II, col. 1723; cfr. también IX, col. 157.

${ }_{33}$ Un buen resumen de los avatares de la empresa de Etiopía puede verse en Francisco RODRIGUES, História da Companhia de Jesus na Assistência de Portugal, Porto, AI, 1931, tomo $1^{\circ}$, vol. II, pp. 565-584.

34 Una carta la escribió en Mozambique a primeros de agosto de 1555, durante su viaje, y probablemente iba dirigida a Francisco de Borja; y la otra la envió a Baltasar Dias desde Baçaim en diciembre del mismo año; cfr. DI, III, pp. 283 y 354 . Es fácil pensar que en su larga experiencia misionera escribiera bastantes más cartas, de las cuales no nos ha llegado ninguna referencia.

${ }^{35} \mathrm{El}$ texto se conserva en copia realizada en Goa ese mismo año: DI, IV, pp. 551-555.

${ }^{36}$ Escribe el P. Jerónimo: «Â sesta-feira se fez todo oficio cantado, e acabando a misa fomos con o Santissimo Sacramento [...], e levando cada menino vestido hum martirio da paixão e as Marias cantando os euses, e outro coro respondendo en quanto d'orgão, todos con suas alvas vestidas [...]; cantou hum menino huma lamentação de Nosa Senhora» (DI, IV, pp. 553-554).
}

Órdenes religiosas

Hispania Sacra 54 (2002) 
- Carta en portugués a los jesuitas de Goa, escrita en Cochim el 21 de agosto de 1560, también por encargo de Melchior Nunes Barreto ${ }^{37}$, en la cual narra algunos sucesos acaecidos en el Cabo de Comorim.

- Carta en portugués a Diego Laínez, escrita en Mannâr el 27 de noviembre de $1561^{38}$. Esta carta es una especie de autobiografia dirigida al General de la Compañía. Tras comentar su relación con algunos discípulos del Maestro Ávila, según ya hemos referido, relata cómo conoció la Compañía. Recuerda su paso por Plasencia, su envío «ao Preste» y su trabajo en la India. A lo largo de la carta muestra repetidamente no estar satisfecho de su formación intelectual: «fiquei-me asi falto de gramatica, que apenas emtendo senão algum latim muito claro e facil» (DI, V, p. 235). Tratando de sus predicaciones en Baçaim, nos sorprende con estas curiosas palabras: «Sabe Deus quamtos herros devi de fazer por mais não entemder. $O$ que me esforçava hera não estar alli casa de dominicos, porque nom hay cousa que mais temá que preguar donde elles estão, por a desconfiamça de minhas letras e pouco saber» (DI, V, p. 236). Consecuencia de ello es la solicitud al padre general para «mandar recado que não preguase».

- Misiva en castellano a Diego Laínez, escrita en Cochim el 11 de enero de $1563^{39}$. El P. Cuenca pide ser desligado de la fallida misión de Etiopía, de modo que el padre general «me mande licencia para que por ella el Provincial sin escrúpulo me pueda mandar o para Japón o para la China» (DI, V, p. 721).

- Carta en castellano a Francisco de Borja, escrita igualmente el 11 de enero de $1563^{40}$. Jerónimo de Cuenca le dedica unas calurosas palabras: «porque, allende de las mercedes que el Señor me tiene echas, cuento ésta por una dellas averme allado en collesios adó V.R. estuviese días, como fue el de Medina del Canpo y Plasencia» (DI, V, p. 723), para después reiterar a Borja, que le había elegido para Etiopía, la misma petición que le hacía a Laínez de poder marchar a las misiones de Extremo Oriente.

- Epístola escrita en Mannâr y dirigida a los jesuitas de Lisboa (S. Roque), lleva fecha del 16 de diciembre de $1573^{41}$; en ella trata de la administración de los sacramentos en la isla, especialmente del bautismo.

\footnotetext{
${ }^{37}$ Se conserva una copia realizada en Goa ese mismo año: DI, IV, pp. 600-603.

38 Original firmado por el P. Cuenca: DI, V, pp. 232-237.

39 Autógrafo: DI, V, pp. 719-722.

40 Autógrafo: DI, V, pp. 722-725.

${ }^{41}$ Se conserva a través de una traducción italiana contemporánea, probablemente realizada en Lisboa: DI, IX, pp. 297-299.
} 
- Finalmente, otra carta (en castellano, pero con bastantes lusismos) enviada desde S. Tomé al P. Everardo Mercuriano, General de la Compañía, el 24 de noviembre de $1575^{42}$. En ella, después de hacer un encendido elogio del P. Valignano, traza su propio recorrido vital como ya hiciera catorce años antes para el P. Laínez: «Quiero ahora dar cuenta a V. P. de mí pues soy su oveja. Soy de Castilla, nacido en Medina del Campo...» (DI, X, p. 127). Informa al P. General de que dos meses antes había hecho los votos de coadjutor formado y hace el recuento de su vida: «Vine a estas partes de la Yndia abrá 21 años. Lo más del tienpo que sería 12 años, estuve en compañía del Pe. Anrríquez en la Costa y Manar [...]. Al presente podré ser de edad de 51 años y nueve meses». $Y$ termina pidiendo que le envíe alguna reliquia.

Sobre él tenemos, además, varios testimonios de sus compañeros y superiores en los informes oficiales de la Orden. De él informa en noviembre de 1559 el P. Melchior Carneiro: «El Pe. Cuenca vino de Castilha para hir al Preste, parece bueno naturalmente, no tiene la conversación mui religiosa, predica $\mathrm{i}$ haze fruito, paréceme que es obidiente, i paréceme algo regalado» (DI, IV, p. 423). Por esas mismas fechas el P. Cabral escribe: «Prega arezoadamente, parece firme na vocação, fiel e virtuoso, tem huma condição afabil» (DI, IV, p. 457) $)^{43}$. Años después, el 12 de diciembre de 1584, escribía Valignano sobre el P. Jerónimo: «es buen religioso y virtuoso, aunque es possilánime para con sus súbditos y de pequeño coraçón que luego se ahoga [...] es de mucha confiança y buen obrero» (DI, XIII, p. 668). En el catálogo de diciembre de 1587, aparece como «superior et concionator lusitanorum» (DI, XIV, p. 799).

Después de tener varios destinos como superior en el sur de la India, en Manar y São Tomé, murió en 1588 en la Costa de la Pesquería, cuando contaba 64 años. La carta anua escrita el 12 de noviembre de ese mismo año, al dar cuenta de la muerte de este hombre sencillo y humilde, recuerda que «hera $o$ deradeiro dos que de Portugal vierão na misão do Preste» (DI, XV, p. 73) ${ }^{44}$.

\section{FRANCISCO DE CARRIÓN, MISIONERO PROTOMÁRTIR DEL JAPÓN}

El año 1557 fue el de la fundación canónica del colegio de Medina del Campo, pero también el de la llegada de Juan Bonifacio, el que sería después ilustre pedagogo y maestro del joven Juan de Yepes, quien estudió allí entre

42 Se trata de un autógrafo: DI, X, pp. 125-130.

${ }^{43}$ Cfr. DI, IV, p. 401,469 y 518.

44 Cfr. DI, XV, pp. 197, 201, 223, 397 y 444; VALIGNANO, p. 311; y GonÇALVES, II, 141. 
1559 y $1563^{45}$. Por aquellos años pudo conocer a un niño igualmente de origen cristiano nuevo ${ }^{46}$, que andaba por las calles de Medina. Se llamaba Francisco de Carrión y había nacido hacia 1552. Estudió cuatro años de Gramática y uno y medio de Lógica ${ }^{47}$, probablemente en Salamanca. Lo que es seguro es que en la ciudad del Tormes ingresó en la Compañía, en junio de 1571. En la Biblioteca Universitaria de Salamanca hemos encontrado la fórmula manuscrita de su ingreso:

«El hermano Francisco de Carrión, natural de Medina del Campo, diocesis de Salamanca, fue recebido en este collegio de Salamanca por el Pe. $\mathrm{M}^{\circ}$. Gil Gonçalez preposito provincial; fue examinado en la lection que le mandaron leer, y aviendo visto el extracto de las constituciones y bullas, y no aviendo impedimento alguno, fue contento de pasar por todo, a 14 de Junio de $1571 »^{48}$.

Sigue la firma de Pedro de Soria y del propio Francisco de Carrión, que hace el número 69 dentro del cuadernillo que lleva por título «Los que an entrado en la Compañía desde el año de sesenta y nueve, siendo Provincial el Pe. $\mathbf{M}^{\circ}$. Gil Gonçalez y Rector el Padre Gutierrez», es decir, Gil González Dávila (1532-1596) y Martín Gutiérrez (1524-1573), respectivamente ${ }^{49}$. Dos años después hizo sus primeros votos en el mismo colegio de Salamanca ante el P. Jerónimo Ripalda (c.1537-1618)

Hacia el mes de octubre de 1573, llegó a Salamanca el P. Baltasar Álvarez (1533-1580) como rector del colegio. Si no le conoció en Medina, durante sus

\footnotetext{
45 Cfr. Luis FERnÁNDEZ MARTín, «El colegio de los jesuitas en Medina del Campo en tiempo de Juan de Yepes», en Nueva Miscelánea Vallisoletana, Valladolid, Grapheus, 1998, pp. 295-314.

${ }^{46}$ Cfr. Ángel SANTOS, «Évora y el espíritu misionero de los jesuitas en Portugal», Miscelanea Comillas, 38 (1962), p. 190

${ }^{47}$ Cfr. DI, X, p. 36.

48 Primero Libro antiguo de los que en este Colegio de la Compañia de Jesus de Salamanca han sido recebidos a la Compañia, desde el año de 1554 hasta el de 1589 y 28 dias de Abril, ms. 1547 de la Biblioteca General de la Universidad de Salamanca, f. $56 \mathrm{v}$. Al margen hay una nota que dice: «Deste V. Varon vease el Martirologio de la Compañia, pag. 152», nota que se refiere al libro de Alegambe, que citamos más adelante, y que además está en relación con su inclusión al comienzo de dicho manuscrito dentro de la lista de «Martires tocantes a este Colegio, de los quales hace memoria este libro" (f. 1r).

49 Seis años antes había ingresado en el Colegio de Salamanca el medinense Gregorio de Valencia (en 1565), después ilustre teólogo; y por las mismas semanas que Francisco de Carrión entraban como novicios, en el mismo Colegio, Francisco Pérez y Juan de la Torre, ambos naturales de Medina del Campo.

50 En el Libro de los que hacen los votos en la Compañia, f. $7 \mathrm{v}$, puede leerse la fórmula latina de sus votos seguida de estas palabras: «En el año de mill y quinientos y setenta y tres, a primero de Junio en el Collegio de la Compañía de Jesus de Salamanca hizo los votos simples el Hermano Francisco de Carrión segun la forma sobre dicha, ante el Pe. $\mathrm{M}^{\circ}$ Hieronymo de Ripalda [...]. Y firmolo de su nombre el dicho Hermano. +Carrion+»; ms. 357 de la Biblioteca General de la Universidad de Salamanca.
} 
años como rector y maestro de novicios, Carrión pudo tratar a Baltasar Álvarez, al menos durante unos meses. No tenemos datos concretos sobre la influencia que Baltasar Álvarez pudo ejercer sobre él, pero ésta pudo ser significativa $^{51}$. La cuestión es que a finales de 1573 pasó por allí el P. Vicente Lenoci, que juntamente con el P. Alessandro Valignano estaba recorriendo España y reclutando religiosos para la misión del Japón ${ }^{52}$. El P. Lenoci escribía desde Salamanca el 8 de enero de 1574: «Io hoggi mi parto da Salamanca et meno meco quatro altri, duoi studianti e duoi coadiutori» (DI, IX, p. 65). Uno de los «dos estudiantes» que se alistaron fue Francisco Carrión, señalado por Lenoci como «il Fratello Carrione, bacciliero» (DI, IX, p. 68). En el «Catálogo de los que van a la India» realizado en febrero de 1574 podemos leer: «Hermano Francisco Carrión, natural de Medina del Campo, diócesi de Salamanca, de 22 años, los 3 de Compañía, hizo los votos a los dos, avía oýdo el curso de Artes antes que entrase, y en la Compañía lo ha buelto a passar» (DI, IX, p. 148). Otro catálogo hecho un mes más tarde, añade sobre él: «buena espettatione» (DI, IX, p. 242).

De este modo marchó a la India dentro de la expedición dirigida por el $\mathrm{P}$. Alessandro Valignano (1539-1606), el napolitano llamado a ser el genio organizador para la evangelización del Extremo Oriente. Los barcos se despidieron de Lisboa a mediados de marzo de 1574 y llegaron a Goa a principios de septiembre de ese mismo año. En ellos iban 42 jesuitas: 25 españoles, 8 portugueses y 6 italianos ${ }^{53}$. Al llegar a la India, quedó destinado en Goa para estudiar Teología ${ }^{54}$. No tenemos muchas noticias de este tiempo, pero sí sabemos que en 1577 llegó a Japón y pronto aprendió la lengua japonesa ${ }^{55}$.

51 Luis DE LA PUENTE atribuye las vocaciones al Japón surgidas en el colegio salmantino al ambiente que supo crear el P. Álvarez entre los estudiantes: «Con sus pláticas en común y en particular, y con los demás medios que aplicaba con suavidad y fortaleza, juntó en Salamanca el fervor sustancial del noviciado de Medina, con la profesión de letras a que allí se atendía. Cuyo testimonio puede ser que, llegando entonces al colegio el Procurador de la India Oriental e Islas del Japón, con licencia de nuestro Padre General para llevar algunos de los que se ofreciesen a esta misión tan gloriosa y tan dificultosa, fue extraordinario el fervor que el Señor les comunicó en pedirlo [...]. Y si no se pusiera tasa, se despoblara el Colegio, por la grande instancia e importunación que todos hacían, procurando, con santa emulación, cada uno vencer al otro en la demanda, con las razones que alegaba para ser preferido. Con ser tantos los llamados, no fueron más que cinco los elegidos para esta jornada», Vida del Padre Baltasar, Madrid, Apostolado de la Prensa, 1943, p. 329.

52 Cfr. León LOPETEGUI, «Paso por España del P. Alejandro Valignano», Studia Missionalia, 3 (Roma, 1947), pp. 1-43. El P. Valignano fue desde Alicante a Lisboa, atravesando Valencia, Alcalá, Madrid y Plasencia, mientras su compañero, el P. Lenoci, visitaba los colegios de la provincia de Castilla.

53 Cfr. SouSA, p. 881. Uno de los españoles era el hermano coadjutor Juan Martínez (c.15461617), natural del pueblo vallisoletano de Tiedra, a pocas leguas de Medina del Campo.

${ }^{54}$ MHJ, I, p. 224.

55 Véase el catálogo de diciembre de 1579 en MHJ, I, p. 111.

Órdenes religiosas

Hispania Sacra 54 (2002) 
Las tres cartas suyas que hasta la fecha han sido publicadas ${ }^{56}$ corresponden a este tiempo anterior a su ordenación y salieron a la luz dentro de la colección Cartas de Iapão, editada en Évora en 1598, bajo los auspicios del arzobispo D. Teotónio de Bragança; el cual, aunque había abandonado la Compañía, conservó siempre excelentes relaciones con los jesuitas. Carrión escribió las tres cartas en vísperas de embarcar hacia Macao para ordenarse.

La primera es una carta al P. General de la Compañia, Everardo Mercuriano, escrita en castellano desde Cochinoçu el 10 de diciembre de $1579^{57}$. Esta larga misiva, modelo de carta anua, la escribió por encargo del visitador Valignano. En ella Carrión trata de la situación de la misión japonesa en general, y de las distintas residencias que los jesuitas tenían establecidas. Pero lo que llama la atención son dos aspectos, que por lo demás, son característicos de la primitiva misión del Japón. Por un lado, la situación de «continua perigrinação, e continuamente cercados do perigo da morte» (f. 432v). Y, por otra parte, la enumeración de algunas curaciones extraordinarias $\mathrm{y}$ «outras semelhantes maravilhas» que «obra o Senhor nesta terra por meo do santo bautismo» (f. 439r) ${ }^{58}$.

Dado el hecho de que la edición de Évora presenta todos los textos en portugués, no sabemos cuál era la lengua original en que Carrión redactó las otras dos cartas, aunque fácilmente pudo ser en la misma lengua lusa, especialmente la dirigida a D. Teotónio. En la misiva a los jesuitas de Ximo, escrita en Usúqui en 1579 (CJ, I, ff. 447v-449v), de carácter más personal, destaca la frecuente afirmación de deseos de martirio, tanto suyos como de los misioneros que estaban con él, encontrando expresiones como ésta:

\footnotetext{
«não deixavamos de nos aparelhar pera que o Senhor ordenasse de nós, pondonos em suas divinas mãos, esperando que fossemos tam ditosos que nos fizesse o Señor tam assinalada merce, como era morrer por seu divino amor, alegrandonos muito com tam ditosa sorte» $(\text { f. } 448 \mathrm{r})^{59}$.
}

La razón nos la da el propio Carrión, cuando continúa escribiendo: «mais esperanças teriamos, se alguns, ou todos morressemos porque então era certa a conversão destes reinos, pois que assi se plantou a primitiva igreja» (f. 449r). Pero aunque Carrión y los suyos se alegren porque se les «negoceava a morte por odio que tem a Deos», también sabe que «se fosse pera maior serviço seu,

56 Cfr. SOMMERVOGEL, II, col. 777-778.

57 El original en el Archivo Romano de la Compañía de Jesús (ARSI), sección Jap-Sin, 46, ff. 27r-42v. Texto portugués en la edición de Évora: CJ, I, ff. 432r-447v.

58 Vid. el capítulo dedicado a «Los carismas en la obra de la conversión», en Jesús LóPEZ-GAY, El catecumenado en la misión del Japón del s. XVI, Roma, PUG, 1966, pp. 190-228.

59 Cfr. Jesús LÓPEZ-GAY, «Las corrientes espirituales de la misión del Japón en la segunda mitad del siglo XVI» (1 ${ }^{\mathrm{a}}$ parte), Missionalia Hispanica, 28 (1972), pp. 353-355. 
elle nos livraria de todos nossos imigos, pois que nem o demonio, nem seus ministros tem mais poder, que o que o Señor lhes concede» (f. 448v), palabras que repiten otras que Francisco Javier había escrito treinta años antes y que seguramente el jesuita medinense conocería bien ${ }^{60}$.

La tercera carta tiene por destinatario a D. Teotónio de Bragança (CJ, I, ff. $453 \mathrm{v}-454 \mathrm{v}$ ), y la escribió el 15 de diciembre de 1579 respondiendo a otra anterior enviada por D. Teotónio: «Aqui em Japão recebemos huma carta de vossa Senhoria com huma boceta chea de Agnus Dei, e 4 Relicairos, e algumas contas de grande estima» (f. 453v). Francisco Carrión, que probablemente le habría conocido en Salamanca, no sabía que D. Teotónio había sido nombrado arzobispo de Évora el año anterior, pues supone que está en la capital salmantina: «As novas que vossa Senhoria deseja saber de Japão se escrevem largamente na carta anua, a qual se manda a Portugal, e a Roma, e conforme ao costume da Companhia ha de ir tambem a ter a esse Collegio de Salamanca» (f. 454r) ${ }^{61}$. En ella el P. Carrión se limita en esta breve epístola a hacer un rápido resumen de la situación de los jesuitas en Japón.

En Macao, en la primavera de 1580, Francisco Carrión fue ordenado sacerdote juntamente con otros tres compañeros de la misión japonesa ${ }^{62}$. El obispo ordenante fue Melchior Carneiro, el mismo que, destinado a Etiopía, había viajado al Oriente veinticinco años antes en compañía de los medinenses Jerónimo de Cuenca y Andrés González. A mediados de ese mismo año, Carrión regresó a Japón y estuvo en Nagasaki hasta 1581. En 1582 misionó en la zona de la capital, Azuchi, Takatsuki, Okayama y Eboshigata. En 1584 estaba en Azuchi y tres años después pasó a la ciudad de Yamaguchi. Finalmente, fue superior de la misión de Hirado y sus islas ${ }^{63}$. De este tiempo no conservamos ningún escrito suyo, solamente tenemos noticia de una carta escrita en noviembre de 1588 y conservada indirectamente a través de un sumario «tirado de algumas cartas» ${ }^{64}$.

Francisco Carrión, después de «ser mui grande obrero» (MHJ, I, p. 339), murió con 38 años en la isla de Ikitsuki (Hirado) el 23 de julio de 1590, según

\footnotetext{
60 Vid. Epistolae S. Francisci Xaverii, Roma, MHSI, 1996, II, p. 149; cfr. p. 65.

${ }^{61}$ En efecto, D. Teotónio había vivido en Salamanca varios años, hasta que en junio de 1578 fue nombrado obispo auxiliar de Évora.

62 Los otros tres jesuitas eran el riojano Francisco Laguna, el portugués Luís de Almeida y Miguel Vaz, natural de la India; cfr. Diego PACHECO, «Luís de Almeida, 1525-1583. Médico, Caminante, Apóstol», Studia, 26 (Lisboa, 1969), pp. 98-101.

63 Vid. FRÓIS, III, pp. 134 y 337; y IV, pp. 317, 319, 322 y 339.

64 Cfr. Josef Franz SCHÜTTE, Introductio ad Historiam Societatis Iesu in Japonia (1549-1650), Roma, IHSI, 1968, pp. 124 y 531.
}

Órdenes religiosas

Hispania Sacra 54 (2002) 
parece envenenado por el tono $-\mathrm{o}$ señor feudal - de $\mathrm{Hirado}^{65}$. Su muerte es relatada por Pedro Gómez, viceprovincial, con estas palabras:

«De estos dos que este año fallecieron, el P. Teodoro Manteles, estando en la dicha residencia con el P. Francisco Carrión muy sanos y bien dispuestos, después de la cena comenzaron enseguida a hallarse mal, y en tres días falleció el P. Carrión, vomitando sangre continuamente, efecto propio de una suerte de ponzoña que suelen dar en Japón» ${ }^{66}$.

A propósito de la suerte final del P. Carrión comenta Juan Ruiz de Medina, después de tratar de algunos laicos que habían sufrido el martirio con anterioridad:

«Se suele decir que los primeros misioneros martirizados en Japón fueron seis franciscanos y tres jesuitas muertos en Nagasaki en 1597. En realidad los protomártires misioneros fueron cuatro jesuitas envenenados en Hirado en 1590 y 1592: el español Francisco Carrión, el portugués Jorge de Carvalhal, el flamenco Teodoro Mantels y el italiano José Forlanetti [...] Los documentos de la época consideran razonablemente a los cuatro como verdaderos mártires ${ }^{67}$.

A partir de entonces fue considerado como mártir, y así aparece, por ejemplo referrido en el libro Mortes illustres de Alegambe ${ }^{68}$. En todo caso quedan abiertos algunos interrogantes acerca de estas muertes (sus causas y circunstancias), ya que se anticipan en varios años a las grandes persecuciones sufridas por el cristianismo en Japón ${ }^{69}$.

65 Vid. LUIS GUZMÁN, Historia de las misiones de la Compañía de Jesús en la India Oriental, en la China y Japón [1601] Bilbao, Mensajero, 1891, p. 576. Cfr. ÉLESBAN DE GUILLERMY, op. cit., II, pp. 595-596.

${ }^{66}$ Copia en la Biblioteca de la Real Academia de la Historia (BRAH), Cortes, leg. 565, f.1r.

67 Juan RUIZ-DE-MEDINA, El martirologio del Japón, 1558-1873, Roma, IHSI, 1999, p. 284.

68 Philippo Alegambe, Mortes illustres et gesta eorum de Societate Iesu, Romae, Typ. Varesii, 1657, pp. 152-153: «Firandum ad opus Evangelii missus, tantam ibi stragem impietatis egregius Christi miles edidit, ut cum aequis animis eam Ethnici ferre non possent, toxicum ei miscuerint genti familiare, quod viscera haurientis contorta discruciat, et copioso prius sanguine constituta vomitione provocato, tandem et animam ipsam corpore exturbat. Id cum imprudens sumpsisset Franciscus, nec domare posset alexiteriis, triduo per ingentes acto cruciatus, vitam demum in Firandensis Insulae vico Ikizuki, honesta morte coronavit». Cfr. M. TANNER, Societas Iesu usque ad sanguinis et vitae profusionem, Pragae, 1675, pp. 251-254, que incluye un grabado alusivo al martirio del P. Carrión.

${ }^{69}$ Cfr. Antonio CABEZAS, El siglo ibérico del Japón, Valladolid, Universidad, 1995, p. 238. 


\section{PEDRO MOREJÓN, COMPAÑERO Y TESTIGO DE LOS MÁRTIRES}

Pedro Morejón es cronológicamente el último de los cuatro medinenses que estamos considerando y, sin duda, el que alcanzó mayor proyección. Hombre de relevantes cualidades, logró gran conocimiento de la cultura y el carácter nipones $\mathrm{y}$, como vamos a ver, era considerado una de las primeras figuras de aquella misión. Ello explica el que le dediquemos mayor espacio en nuestro trabajo.

\subsection{Datos biográficos}

Pedro Morejón nació en Medina del Campo en 1562 en el seno de una de las familias más nobles de la ciudad castellana ${ }^{70}$. Entró en la Compañía en 1578 y es casi seguro que hizo su noviciado en Villagarcía de Campos, donde el año anterior habían sido instalados el noviciado y la tercera probación de la provincia. En ese caso pudo tener como primer maestro al ya referido P. Baltasar Álvarez, quien había sido trasladado desde Salamanca a finales de 1576 y que permanecería en Villagarcía hasta la primavera de 1578, y después al P. Juan de Sigüenza.

Más tarde pasó a Salamanca, en cuya Universidad Fray Luis de León desplegaba por entonces su magisterio más maduro. De este modo, encontramos el nombre de Pedro Morejón (o Morexón), como «teólogo», en los libros de matrículas de la Universidad salmantina en los cuatro cursos académicos, correspondientes a los años 1582-83, 1583-84, 1584-85 y $1585-86^{71}$. Este último lo dejó a la mitad, pues en febrero de 1586 salió del colegio salmantino y marchó al Oriente, llegando a Goa ese mismo año. En Goa fue ordenado sacerdote al año siguiente, y allí realizó la «tercera probación», según consta en el catálogo de diciembre de $1587^{72}$.

En 1588 fue destinado al Japón, pero no llegó a Nagasaki hasta julio de 1590 en una expedición formada por catorce misioneros, juntamente con la célebre embajada de los cuatro fidalgos japoneses que volvían a su patria, des-

70 El linaje Morejón era uno de los siete que gobernaron Medina del Campo en la Edad Media y tenía enterramiento en la iglesia del convento de san Francisco. El nombre de la calle Morejón que aún perdura en Medina hace referencia a este linaje, no a Pedro Morejón en particular; informaciones recibidas de D. Ricardo Sendino, Cronista Oficial de la Villa.

71 El nombre de Morejón aparece en los Libros de matrículas (Archivo de la Universidad de Salamanca), incluido en el «Colegio y monasterio del santisimo nombre de Jesús de Salamanca», en los ff. $16 \mathrm{r}, 15 \mathrm{v}, 18 \mathrm{r}$ y $9 \mathrm{r}$, respectivamente en relación a los cuatro cursos mencionados.

72 Vid. DI, XIV, p. 793.

Ordenes religiosas

Hispania Sacra 54 (2002) 
pués de haber recorrido varios países de Europa ${ }^{73}$. Curiosamente su llegada coincide en el tiempo con la muerte de Francisco Carrión. Por entonces la misión japonesa se había convertido en la más importante y prometedora cristiandad de Oriente.

Pedro Morejón aprendió la lengua japonesa rápidamente, pues ya el catálogo de noviembre de 1592 dice de él: «P. Pero Morejón, Castelhano, sabe bem e prega japão» (MHJ, I, p. 291). Y en el de junio de 1593 podemos leer: «P. Pero Morijón, Castellano, de Medina del Campo, diócesi de Salamanca, de 30 años de edad, de mediocres fuerças, de 16 años de la Compañía. Acabó sus estudios. Sabe muy bien la lengoa de Japón» (MHJ, I, p. 314). Y, evidentemente, esta observación sobre su dominio del japonés sigue apreciendo en los catálogos siguientes ${ }^{74}$.

En diciembre de 1592, siendo superior de la residencia de Shiki, bautizó a Vicente Kaun, primer coreano cristiano de nombre conocido, más tarde jesuita, que sería martirizado en $1626^{75}$. Veinte años más tarde el P. Morejón recordará con cariño a estos coreanos que llegaron a Japón, y en especial a los bautizados por él: «gente de grande capacidad y ingenio, blandos, dóciles y de lindos naturales» ${ }^{76}$.

Posteriormente fue destinado a Osaka, donde convivió varios años con el hermano Pablo Miki (1564-1597), el joven catequista Juan de Goto (15781597), y el ayudante Diego Kisay (1533-1597). Eran vísperas de la persecución de Hideyoshi, y a pesar de las diligencias de Morejón para librarlos, los tres muy pronto serían mártires. A él le correspondería escribir sobre ellos y contribuir a su beatificación en $1627^{77}$.

Eran también tiempos de desgraciadas controversias entre las órdenes religiosas que misionaban en el Imperio del sol naciente. Según el comisario franciscano Fray Pedro Bautista (c.1542-1597), Morejón «ayudava al obispo» de Japón, Pedro Martins, en algunas discusiones con los franciscanos ${ }^{78}$. Pero al mismo tiempo, dado que ambos tenían su residencia en Osaka, trataba con alguna familiaridad con los franciscanos Martín de la Ascensión (1567-1597),

\footnotetext{
73 Vid. Fróls, V, p. 186.

74 Vid. MHJ, I, pp. 449, 586, 602, etc.

75 Vid. Juan RUIZ-DE-MEDINA, Orígenes de la Iglesia católica coreana, desde 1566 hasta 1784, Roma, IHSI, 1986, pp. 69-70 y 155-158.

${ }^{76}$ Copia en la BRAH, Cortes, leg. 566, f. 461v.

77 Finalmente serían canonizados por Pío IX en 1862, juntamente con los franciscanos Pedro Bautista, Martín de la Ascensión, a los cuales nos vamos a referir a continuación.

78 Carta de Pedro Bautista (18 de diciembre de 1596), en J. I. TELLECHEA, Nagasaki. Gesta martirial en Japón (1597). Documentos, Salamanca, Universidad Pontificia, 1998, p. 296.
} 
que pronto sería martirizado y Marcelo Ribadeneira ${ }^{79}$. De hecho fue Morejón quien la noche del 7 de diciembre de 1596 avisó a Fr. Martín del decreto de prisión contra los franciscanos. Unos meses después, en el verano de 1597, Morejón participaría en el proceso que los jesuitas abrieron, a raíz de los martirios ${ }^{80}$.

Después de hacer, en 1601, la profesión de cuatro votos, trabajó entre 1602 y 1613 en la región central de Japón, donde era rector, y vivía con el futuro mártir Carlos Spínola (1565-1622), que hacía el oficio de ministro ${ }^{81}$. Es éste quien, a propósito de Pedro Morejón, hace esta observación particularmente importante en aquel contexto: «Nunca le hallé pasión de naciones» ${ }^{82}$, para dedicarle a continuación los siguientes elogios:

«Muy devoto, edificativo, de todos habla bien..., lo que él diga será pura verdad, porque hace profesión de decirla y tratarla [...]. Sabe excelentemente la lengua, la historia, sectas, costumbres de la tierra y el origen de esta persecución y de la pasada» ${ }^{83}$.

Entre las varias responsabilidades que durante este tiempo recayeron sobre él ${ }^{84}$, destaca el hecho de que en junio de 1607 participó en una entrevista con el shogún Tokugawa Ieyasu, juntamente con el viceprovincial Pasio y con el célebre João Rodrigues, el intérprete ${ }^{85}$.

En la Congregación Provincial celebrada en Nagasaki en octubre de 1614 fue elegido procurador de la misión de los jesuitas en Japón el P. Gabriel de Matos y al mismo tiempo se eligió a Pedro Morejón como sustituto. El P. Matos viajaría a Europa por la India Oriental hacia Lisboa, y el P. Morejón seguiría la vía de las Indias Occidentales, por Manila y Nueva España. Pocas semanas después, en noviembre de 1614, se produjo un exilio masivo de misioneros, que tuvieron que refugiarse en Filipinas y con los desterrados sale el P. Morejón. En Filipinas enterró a su compañero Antonio Francisco de Critana, muerto durante el viaje.

\footnotetext{
79 Comenta Fr. Marcelo Ribadeneira que en Osaka visitaba al P. Morejón, «y con particular amistad trataba, por ser varón muy religioso y letrado y experimentado en las cosas de Japónn; ; en Historia de las islas [...] y Japón [1601], Madrid, Editorial Católica, 1947, p. 593.

80 Vid. Michael COOPER, Rodrigues, o Intérprete, Lisboa, Quetzal, 1994, pp. 155 y 158.

81 Vid. MHJ, I, pp. 495, 503, 507, etc. Cfr. Juan RUIZ-DE-MEDINA, «Un jesuita de Madrid arquitecto de la iglesia de São Paulo, Macao», Revista de Cultura, II Série, 21 (Macau, 1994), pp. 45 y 49.

82 Cfr. João Paulo OliveirA E COSTA, «A rivalidade luso-espanhola no Extremo Oriente e a querela missionológica no Japão», en $O$ Século Cristão do Japão, Lisboa, Universidade CatólicaUniversidade Nova, 1994, pp. 477-524.

${ }^{83}$ En el ARSI, Jap-Sin, 36, ff. 170r-177r

84 Cfr. AFONSO DE LUCENA, De algumas cousas que ainda se alembra o Pe. Afonso de Lucena que pertencem à cristandade de Omura [1578-1614], ed. por J. F. Schütte, Roma, IHSI, 1972, pp. 60, 129,192 y 284.

85 Vid. Jacques BÉsINEAU, Au Japon avec João Rodrigues, 1580-1620, Lisboa-Paris, CCCG, 1998, pp. 159-160.

Órdenes religiosas

Hispania Sacra 54 (2002)
} 
Pedro Morejón siguió su camino hacia Europa a través de México, anclando en el puerto de Acapulco el 1 de enero de 1616. En ese tiempo recibió la recomendación del virrey de México en carta del 25 de mayo de 1616 en estos términos: «entiendo es persona a quien se puede dar crédito» ${ }^{86}$. Embarcando hacia España, a finales de enero de 1617 estaba en Madrid. Fue a Roma, pero en noviembre de 1617 ya se encontraba nuevamente en Madrid. Desde la capital de España se dirigió a Coimbra y Lisboa.

En la primavera de 1622 se embarcó en Lisboa de nuevo hacia Oriente. Haciendo escala en Goa, siguió su viaje y, al pasar por Siam, intentó fundar allí una residencia, lo cual no fue posible. Continuó por Camboya y Manila y, finalmente, llegó a Macao el 1 de septiembre de 1625, concluyendo así un viaje alrededor del mundo que había durado casi once años.

Posteriormente aún hizo dos viajes a Filipinas (en diciembre de 1625 y en la primavera de 1630), ambos con el encargo de pacificador, lo cual demuestra, una vez más, sus extraordinarias dotes diplomáticas. Precisamente en 1630 Pedro Morejón regaló al Colegio de la Compañía en Manila, una carta autógrafa de Javier, que había sido encontrada en Yamaguchi y que hoy está perdi$\mathrm{da}^{87}$. En uno de estos viajes a Filipinas, además, conoció al historiador dominico Diego Aduarte, quien le cita en su obra ${ }^{88}$; tenemos aquí otro buen ejemplo dela capacidad del P. Morejón para entablar relaciones de amistad con religiosos de otras órdenes.

Entre 1627 y 1631 fue rector del Colegio de S. Paulo en Macao. A partir de abril de 1630, Pedro Morejón actuó como procurador de de la Compañía en el proceso instruído sobre los mártires. En sus últimos años fue consultor del provincial y padre espiritual de la casa de Macao. En noviembre de 1636 le tocó participar en las deliberaciones en que se decidió despedir de la Compañía al célebre Chistóvão Ferreira, antiguo provincial del Japón ${ }^{89}$. Durante este

86 Archivo general de Indias, México, 28, 5, $\mathrm{n}^{\circ} 37$, apud Juan GIL, Hidalgos y samurais. España y Japón en los siglos XVI y XVII, Madrid, Alianza, 1991, pp. 428-429.

87 Sí se conserva, en cambio, el documento de donación: «Doy fe y testimonio que di al Pe. Juan de Bueras, provincial de las islas Filipinas, de la dicha Compañía de Jesús, una carta escrita de la misma mano de el Santo Pe. Francisco Xavier, Apóstol de Japón, cuya letra conozco muy bien por haverla cotejado con otras muchas de su santa mano [...]. Dio conmigo buelta entera al mundo y creo que por ella me libró el Señor de muchos peligros [...]. En Manila, Otubre cinco de mil y seiscientos y trenta. Pedro Morejón»; apud Epistolae Xaverii, II, p. 234.

88 Vid. Diego AdUARTE, Historia de la Provincia del Santo Rosario de la Orden de Predicadores en Filipinas, Japón y China [1640], Madrid, CSIC, 1963, II, p. 287: «el Padre Pedro Morejón, de la dicha Compañía, que fue muchos años ministro del Evangelio en aquellos reinos antes de la persecución, y después de ella fue desterrado de ellos por serlo, viniendo este años a esta ciudad de Manila de la de Macán, a negocios...».

89 En la BRAH, Archivo del Japón, f. 507v. La firma de Pedro Morejón aparece junto a la de Alexandre Rhodes y otros padres. 
último periodo de su vida continuó, por tanto, con puestos de responsabilidad, hasta su muerte, acaecida en Macao el 11 de diciembre de 1639, cuando contaba setenta y siete años ${ }^{90}$.

\subsection{Escritos de Pedro Morejón}

La relevancia de Pedro Morejón está unida a sus escritos, y éstos, al igual que su vida, están íntimamente relacionados con la larga persecución que el cristianismo sufrió en Japón ${ }^{91}$. Algunos de ellos fueron publicados, alcanzando varias ediciones y en distintos países, pero la mayoría quedaron como manuscritos inéditos, los cuales en la actualidad se hallan dispersos en diferentes $\operatorname{archivos}^{92}$.

Durante su larguísima cincunnavegación, el P. Morejón aprovechó para dar a la imprenta dos relaciones en castellano de la persecución: una fue impresa en México (1616), y la otra, que es continuación de la anterior, en Lisboa (1621). La primera está dividida en dos partes que llevan por título, respectivamente, Relacion de una grande persecucion que el Año de 1614 se levanto contra la Yglesia de Iapon y Relacion de la persecucion que huvo estos años contra la Iglesia de Iapon, y los ministros della ${ }^{93}$.

El libro publicado en Lisboa se titula Historia y relacion de lo sucedido en los reinos de Iapon y China, en la qual se continua la gran persecucion que ha avido en aquella Iglesia, desde el año de 615. hasta el de 1994. En realidad, en

90 Cfr. MHJ, I, 1243

91 Nicolás ANTONIO lo presenta así: «PETRUS MOREJON, Medinensis, Jesuitarum sodalis, in Japonia multo pretio operae facto venit Romam procurator illius provinciae, atque inde in eam rediit», Bibliotheca Hispana Nova [1788], Madrid, Visor, 1996, II, p. 219. Cfr. RiBADENEIRA-ALEGAMBESOTUELlo, Bibliotheca Scriptorum Societatis Iesu, Roma, 1676, p. 685; y SOMMERVOGEL, V, col. 1307-1309 y XII, col. 588-589.

92 Véanse a este respecto dos trabajos fundamentales de J. F. SCHÜTTE, «Documentos sobre el Japón conservados en la colección «Cortes»«, Boletín de la Real Academia de la Historia, 147 (1960), pp. 23-60 y 149-259; y El «Archivo del Japón», Madrid, Real Academia de la Historia, 1964. Cfr. también del mismo autor: «Documentos del «Archivo del Japón» en la Biblioteca Nacional madrileña», Missionalia Hispanica, 27 (1970), pp. 59-88; Japón, China, Filipinas en la colección «Jesuitas, Tomos» de la Real Academia de la Historia - Madrid, Madrid, Asociación Española de Orientalistas, 1976; y «Documentos del «Archivo del Japón» en el Archivo Histórico Nacional de Madrid», Missionalia Hispanica, 35-36 (1978-79), pp. 137-283.

93 Méjico, Joan Ruyz, 1616; hemos consultado el ejemplar de la Biblioteca General de la Universidad de Salamanca. La primera parte consta de 110 páginas y la segunda, de 96 . Esta relación fue reeditada varias veces: en México (en el mismo año 1616), en Zaragoza (1617), además de una versión en lengua inglesa (1619).

94 «Por el Padre Pedro Morejon de la Compañía de Jesus, Procurador de la Provincia de Iapon, natural de Medina del Campo», Lisboa, Juan Rodriguez, 1621. En la Biblioteca General de la Univer-

Órdenes religiosas

Hispania Sacra 54 (2002) 
los últimos capítulos se refiere también a las persecuciones sufridas en China y Etiopía. En el «Prologo al lector» Morejón explica:

\footnotetext{
«Pasando por la Ciudad de Mexico de camino para España y Roma, a peticion de los Padres de aquella Provincia, y de otras personas devotas, hize una breve suma de lo sucedido en aquellos Reinos los años de 613. y 14. [...] En esta relacion (que sera como segunda parte) pondre lo sucedido en estos tres, o quatro años siguientes».
}

Y sigue diciendo el P. Morejón como se basa en las informaciones de los mismos jesuitas que están en Japón: «a los quales, y casi a todos los que en esta relacion apunto conoci, y trate familiarmente, por aver estado mas de 30 . años en aquellas partes, y agora buelvo a ayudarles, y acabar lo que me queda de la vida en su santa compañía».

Pedro Morejón continuó esta investigación en los últimos años de su vida, cuando desde Macao se dedicó a reunir todas las noticias posibles sobre los martirios ocurridos en Japón. En las cartas de este tiempo frecuentemente se refiere a sus pesquisas. Así, en la carta de 10 de noviembre de 1625 dirigida al P. Asistente, Nuno Mascarenhas, comenta:

\footnotetext{
«Huma diligência fis aquí que me consolou e cuido dará gosto aos Padres sabe-la, e hé que nestes dez ou once annos que andamos desterrados, do anno de 614 até o de 624 , ouve em Japão 550 gloriosíssimos mártires, sem os que não vierão a nossa notícia, e os que morrérão consumidos de trabalhos e misérias no desterro, que estes forão muitos $\rangle^{95}$.
}

Buena parte de su obra escrita la constituyen, por tanto, las relaciones de los martirios ocurridos en Japón. En 1626, el P. Morejón redactó en portugués un «Rol dos mártyres de Jappão das 4 Religiões» ${ }^{96}$, que incluía a los mártires de las cuatro órdenes religiosas presentes en Japón: jesuitas, dominicos, franciscanos y agustinos.

En 1627, escribió en castellano un nuevo informe, que fue publicado en México (1628) con el título de Triunphos, Coronas, Tropheos de la perseguida Iglesia de Japón ${ }^{97}$, donde trata de los «martirios esclarecidos de nueve religiosos de la Compañía de Jesús y de otros de su familia». Lleva anexa una carta en castellano del propio Morejón, datada en Macao, el 31 de marzo de 1627.

sidad de Salamanca hay tres ejemplares de esta edición, que consta de 193 folios más el prólogo y la tabla final. Éste es el libro citado por SOUSA VITERBo en A Litteratura Hespanhola em Portugal, Lisboa, Imprensa Nacional, 1915, pp. 159-160.

${ }_{95}$ Autógrafo portugués en el ARSI, Jap-Sin, 18, I, ff. 53r-54v.

96 Autógrafo en la BRAH, Jesuitas, leg. 21, ff. 905r-906v.

97 Este relación tuvo varias reediciones en México (1631), Roma y Milán (1632). 
En los años siguientes prosiguen las investigaciones de Morejón, y así el 10 de mayo de 1631 puede escribir una carta al P. Virgilio Cepari, en la que le comunica: «Tengo hecho un Catálogo de los que se sabe murieron por Christo, desde el principio de esta conversión, $\mathrm{y}$ voy haziendo una sumaria relación de su martirio: año, mes, día, lugar, y género de muerte» ${ }^{98}$. El texto referido por Morejón es la Summaria y breve relación de los gloriosos Mártires ${ }^{99}$, que consta de un prólogo y diecisiete capítulos escritos en castellano sobre los martirios ocurridos entre 1557 y 1614. Ese mismo año 1631 escribió en portugués la «Breve Relação dos mártires que em Japão ouve do anno de 627 até o de $630 » 100$.

Hasta el final de su vida siguió Morejón buscando, desde Macao, nuevos datos sobre los mártires de Japón. Así sabemos que su carta de 17 de octubre de $1635^{101}$, dirigida al P. Nuno Mascarenhas, llevaba anexo un catálogo hoy perdido. Hay también otras dos relaciones escritas por mano de Pedro Morejón, y cuya autoría probablemente corresponde al jesuita medinense ${ }^{102}$.

Además de las cartas ya reseñadas, Pedro Morejón escribió otras. Pasamos a enumerar, por orden cronológico, aquellas de las que nos ha llegado noticia, dando cuenta de su conservación actual:

Las primeras cartas suyas que conocemos las escribió a dos franciscanos poco antes de ser martirizados. Una, hoy perdida, la escribió a Fr. Martín de la Ascensión rogándole que, por cuestiones de prudencia, no dijese en Japón que la India de Portugal y Filipinas era todo de un mismo rey ${ }^{103}$. Otra la dirigió «a los Santos Martyres, quando iban camino del Martyrio de sus Cruces») (enero de 1597): esta misiva es la más conocida de Morejón y su texto castellano ha sido publicado en diversas relaciones sobre los protomártires del Japón ${ }^{104}$.

La carta que dirigió al viceprovincial del Japón (Osaka, 29 de agosto de $1601)$, ha llegado hasta nosotros a través de una obra portuguesa del P. Fernão Guerreiro $^{105}$. De este tiempo, anterior a su exilio de Japón, conservamos otras dos cartas en castellano que Pedro Morejón envió al P. Claudio Acquaviva,

98 Original en el ARSI, Jap-Sin, 18, I, f. 96r. El texto está parcialmente editado en MHJ, I, pp. 830-831.

${ }^{99}$ Autógrafo en la BRAH, Jesuitas, leg. 21, ff. 749r-767v.

100 Autógrafo en el ARSI, Jap-Sin, 29, I, ff. 114r-116v., fechado en Macao el 23 de enero de 1631.

101 Original portugués en el ARSI, Jap-Sin, 29, f. 132r.

102 Cfr. SCHÜTTE, El «Archivo del Japón»..., pp. 254 y 256.

103 Declaración de Diego Valdés (17 de junio de 1598), en TELLECHEA, op. cit., p. 315.

$104 \mathrm{El}$ texto puede verse, por ejemplo, en Lorenzo PÉREZ, Cartas y relaciones del Japón, Madrid, 1923, III, p. 213; cfr. SOMMERVoGel, V, col. 1307. No se conserva la carta de respuesta de Fr. Pedro Bautista.

105 Fernam GuerReIRO, Relaçam annal das cousas que fezeram os Padres da Companhia de Jesus [...] nos annos de 602 e 603, Lisboa, Jorge Rodrigues, 1605, ff. 46r-v.

Órdenes religiosas

Hispania Sacra 54 (2002) 
General de la Compañía de Jesús: una desde Osaka (1 de enero de 1603) ${ }^{106}$ y otra desde Miyako (4 de enero de 1613), sobre las razones del edicto de 1612 en el cual Ieyasu prohibía el cristianismo en su feudo personal ${ }^{107}$.

Destacan varias cartas dirigidas al P. Nuno Mascarenhas, encargado en Roma de la Asistencia jesuítica lusitana: desde Madrid, a 24 de noviembre de 1619 (en castellano) ${ }^{108}$; desde Coimbra, a 7 de septiembre de 1620 (en portugués) ${ }^{109}$; Lisboa, 3 de octubre de 1620 (en castellano) ${ }^{110}$; y desde Lisboa, a 14 de noviembre de 1620 (en portugués) ${ }^{111}$, aparte de otras dos ya mencionadas.

Se conservan también otros textos epistolares de Morejón: una carta en portugués dirigida a Luís Lobo y escrita en Méjico (1616) ${ }^{112}$, otra en castellano redactada en Lisboa $(1621)^{113}$, y otra dirigida a Sebastião Vieira, Procurador de la Provincia de Japón en Roma, en portugués (Macao el 15 de noviembre de 1625) ${ }^{114}$.

Aparte de las relaciones de los mártires y de las cartas, Pedro Morejón es el autor de otros escritos breves, como la curiosa propuesta «Acerca de la división de las provincias entre las Religiones en Japón, y casas que cada uno tuvo en Japón» (en castellano) ${ }^{115}$ o las «Declaraciones sobre el modo que tuvo Fr. António do Rosairo» (Macao, 1626), también en castellano ${ }^{116}$.

Por otra parte, Morejón participó en la elaboración de varios documentos colectivos $^{117}$, así como copió algunos documentos escritos por otros, para completar sus informes ${ }^{118}$. También son frecuentes sus anotaciones en los escritos de otros, como sus anotaciones a la obra de Bernardino de Ávila Girón, Relación del Reino de Nippon» ${ }^{119}$ o los «Notados sobre el Libro de los Mártires de Japón, impreso en Manila el año 1625 por Fr. Diego de S. Francisco» (en castellano) ${ }^{120}$, etc.

\footnotetext{
106 Autógrafo en el ARSI, Jap-Sin, 14, I, ff. 114r-115v.

107 Autógrafo en el ARSI, Jap-Sin, 15, II, ff. 221r-223v. Cfr. el comentario que de esta carta hace Antonio CABEZAS, en op. cit., pp. 387-388.

108 Autógrafo en el ARSI, Lusitania, 74, ff. 153r-154v.

109 Autógrafo en el ARSI, Jap-Sin, 17, f. 262r.

110 Autógrafo en el ARSI, Goa, 9, I, ff. 38r-39v.

111 Autógrafo en el ARSI, Goa, 9, I, ff. 40r-v.

112 Copia en el Archivo de la Provincia de Toledo, leg. 1051, $\mathrm{n}^{\circ} 8$.

113 Autógrafo en el ARSI, Jap-Sin, 25, f. 107r.

114 Autógrafo en el ARSI, Jap-Sin, 18, I, f. 55r.

115 El texto está editado íntegramente en MHJ, I, pp. 759-766.

116 Autógrafo la BRAE, Japón, leg. 21, ff. 560r-v.

117 Vid. SCHÜTTE, Archivo del Japón, pp. 233, 236, 237, 394 y 428.

118 Idem, ibid., pp. 364, 414-416, etc; y también MHJ, I, p. 567 y 648.

119 Según Morejón, dicha obra «contiene muchos yerros por la poca noticia que tenía de Japón, aunque él se precia que la tenía», en el ARSI, Jap-Sin, 49, f. 149r.

${ }^{120} \mathrm{El}$ autógrafo en el ARSI, Jap-Sin, 61, 64r-70v. Incluye el testimonio, en el proceso de beatificación de los mártires japoneses, sobre el supuesto martirio de Muruyama Toan de Antonio».
} 


\section{CONSIDERACIONES FINALES}

A lo largo del presente trabajo hemos podido seguir el rastro de cuatro jesuitas diferentes entre sí - como diversas han sido las fuentes consultadas en cada caso, dependiendo de la disponibilidad de las mismas-, cuyas vidas juzgamos de interés. Los cuatro nacieron en Medina del Campo, se hicieron jesuitas en la antigua provincia de Castilla y pasaron después a las misiones portuguesas de Asia. Conjuntamente cubren el primer siglo de historia de la Compañía de Jesús, trabajando en diversos lugares dentro del amplísimo Oriente y correspondiendo a tres momentos diferentes.

Jerónimo de Cuenca y Andrés González son hombres que nos hablan de los primeros pasos de la Compañia en España. Ambos están entre los fundadores de las casas de Plasencia y Ávila, respectivamente, y son cronistas de esos inicios. Los dos fueron enviados al mismo tiempo a la misión de Etiopía, pero ninguno llegó a este destino, aunque por diferentes motivos, según hemos señalado. Francisco Carrión acompañó a Valignano en la famosa expedición de 1574, trabajó en Japón durante los años más prometedores de aquella misión, y murió envenenado, muy probablemente como mártir. Pedro Morejón es sin duda el más relevante de los cuatro, por los cargos que le tocó desempeñar en los tiempos recios de la persecución contra el cristianismo en Japón. De él conservamos un mayor número de textos, tres de los cuales fueron publicados como libros que llegaron a tener varias ediciones y en distintos idiomas, como hemos podido ver.

Finalmente queremos recordar que, en aquellas tierras, los jesuitas de alguna manera representaban a Portugal, aunque fueran españoles - como los cuatro que hemos estudiado- o italianos. Los jesuitas no sólo pertenecían a la Asistencia de Portugal, sino que pasaban por un proceso de lusitanización -es verdad que no todos en el mismo grado-, desde el momento en que viajaban al Oriente partiendo de Lisboa y haciendo el recorrido por Mozambique y Goa, hasta Malaca, Macao o Japón ${ }^{121}$. En este trayecto, todos los jesuitas no nacidos en Portugal aprendían la lengua lusa. Esto les permitía escribir tanto en portugués como en castellano, como hemos podido ver al señalar sus escritos localizados, siendo así muestra del bilingüismo luso-castellano tan frecuente en los siglos XVI y XVII ${ }^{122}$. Y buena prueba de esa lusitanización a la que nos esta-

\footnotetext{
${ }^{121}$ Frente a esto, los jesuitas de Filipinas y los frailes mendicantes que llegaron al Extremo Oriente a partir de finales del siglo XVI, en alguna medida, representaban a España. Todos ellos embarcaban en Sevilla, viajando por México y Filipinas.

122 Cfr. Eduardo Javier ALONSO ROMO, Los escritos portugueses de san Francisco Javier, Braga, Universidade do Minho, 2000, pp. 143-185; y también, «A lusitanização de S. Francisco Xavier e dos seus companheiros espanhóis (1540-1552)», Brotéria, 147 (Lisboa, 1998), pp. 565-580.
} 
mos refiriendo son los lusismos de todo tipo que encontramos en los textos castellanos. Y esto, en principio, vale también para el Japón, que, como es sabido, nunca formó parte del imperio portugués, aunque es verdad que allí con el tiempo, hubo diversos conflictos en relación a este asunto. Queremos subrayar esto frente a otros autores que han incidido en la castellanización de Portugal y sus territorios en aquellos años ${ }^{123}$.

El estudio podría completarse con otros jesuitas que, no siendo naturales de Medina del Campo, vivieron allí algún tiempo - principalmente durante su noviciado- y que después marcharían después al Oriente: el logroñés Gil Martínez de la Mata (1547-1599) y el soriano Francisco Calderón (15501618). Queremos recordar que el medinense Gaspar de Loarte (1498-1578), jesuita y discípulo de san Juan de Ávila, nunca salió de Europa, pero dos tratados suyos llegaron a Japón en versión portuguesa, y allí fueron traducidos al japonés y publicados dentro de un manual de meditaciones que recibió el título de Spiritual Shugyô (1607) ${ }^{124}$.

Señalemos, por otra parte, que en Brasil sólo hemos encontrado la referencia a un jesuita medinense: el hermano cocinero Juan Sánchez, nacido hacia 1559 que entró en la Compañía en $1587^{125}$. En todo caso, nos parece que vale la pena seguir estudiando la expansión ibérica del siglo XVI a través de aquellos hombres que, con su vida y sus escritos, trabajaron incansablemente tan lejos de su tierra natal.

123 Vid. Pilar VÁZQUEZ CUESTA, «La lengua y la cultura portuguesas», en Historia de España "Menéndez Pidal», Madrid, Espasa-Calpe, 1986, t. XXVI, vol. II, pp. 467-563.

124 Se trata de los libros Instrução e avisos para meditar os mistérios do Rosário e Instrução e advertências para meditar a paixão de Cristo; cfr. Jesús LÓPEZ-GAY, «Las corrientes espirituales...», pp. 356-357.

125 Juan Sánchez aparece en los catálogos de la Provincia de Brasil de los años 1598 y 1600; cfr. Charlotte de CASTELNAU-L'Estolle, Les Ouvriers d'une Vigne stérile, Lisbonne-Paris, CCCG, 2000, p. 551. También el toledano Francisco Pérez Godoy (c.1540-1570), que había ingresado en el noviciado de Medina del Campo, se dirigía a Brasil cuando fue martirizado en compañía del beato Inácio de Azevedo y otros treinta y ocho jesuitas. 